\title{
Çeviri Eğitiminde Türkçenin Dil Bilgisi: İşlevsel Yaklaşım
}

\author{
Öğr. Gör. Dr. Olena Kozan \\ Ankara Hacı Bayram Veli Üniversitesi, Edebiyat Fakültesi \\ Rus Dili ve Edebiyatı Bölümü \\ olena.kozan@gmail.com
}

Öz

Bu çalışmada çeviri eğitimi gören öğrencinin ana dili olan Türkçeye yönelik yapısal bakış açısının çeviri sürecinde yol açtığı sorunlar dile getirilmektedir. Bununla birlikte çeviri eğitiminde yapısal yaklaşımı sergileyen geleneksel dil bilgisi ders kitaplarının yanı sıra Türkçeye yönelik işlevsel yaklaşım doğrultusunda betimlemelerin geliştirilmesi gerektiği fikri ileri sürülmektedir. Çalışmada öğrencinin ortaokuldan itibaren alıştığ 1 Türkçeye yönelik yapısal yaklaşımın, hedef dile çeviri sürecinde Türkçenin "dünya görüşüne" göre türetilmiş yapıların ortaya çıkmasını tetikleyebildiği gösterilmekte ve yabancı dil/çeviri bölümlerinde okuyan öğrencilerin başvurdukları ders kitapları başta olmak üzere konu ile ilgili kaynakların yetersizliği üzerinde durulmaktadır. Çalışmada ana dili Türkçe olan ve Türkçenin yapısal boyutu üzerinde odaklanan, geleneksel Türkçe dil bilgisi ile çeviri sürecini öğrenmeye çalışan öğrencinin çeviri eğitiminde karşılaşabildiği sorunlar TürkçeRusça dil çiftine yönelik örneklerle gösterilmiştir. Odak noktası, geleneksel Türkçe dil bilgisinde "sıfat-fiil" olarak adlandırılan ve Türkçe-Rusça çeviri sürecinde sorun oluşturabilen - $d \imath k$ - yapıları olmuştur. Sosyo-politik metinlerin ayrılmaz bir unsuru olan - $d_{\imath} k$ yapılarının Türkçe-Rusça çeviri sürecinde işlevsel çözümlenmesinin şart olduğu gösterilmiştir. Çalışmada çeviri eğitimi gören öğrencinin kendi ana diline yönelik işlevsel bakış açısının önemi vurgulanmıştır.

Anahtar Kelimeler: Çeviri eğitimi, Türkçenin dil bilgisi, Türkçe-Rusça çeviri, işlevsel yaklaşım.

\section{The Grammar of Turkish in Translation Training: Functional Approach}

\begin{abstract}
The article deals with the problems in the translation process caused by the structural approach to Turkish adopted by the students of translation, with Turkish being their native language, and highlights the necessity to develop a functional approach to Turkish in translation teaching alongside the traditional grammar books with a structural paradigm. The structural approach to Turkish adopted by the students since elementary school is seen to be a triggering factor behind the words, phrases, sentences and texts derived according to the "linguistic worldview" of Turkish language during the translation into the target language. Thus, the problem of university coursebooks on Turkish as well as other sources on the subject used by the students of translation is introduced. The article reveals the problems encountered during the translation training/foreign language learning by the


native Turkish students who try to apply the traditional Turkish grammar focusing on structural level of the language, with examples given for the Turkish-Russian language pair. The main focus of the article is the - $d i k$ structures known as "sifat-fiil" in Turkish grammar that can cause problems in Turkish-Russian translation process. The necessity of applying functional analysis to the $-d \imath k$ structures, being an inseperable element of the socio-political texts, in the translation process is underlined. The importance of functional approach perspective for the native language to be developed by the student studying translation is emphasized.

Keywords: Translation training, Turkish grammar, Turkish-Russian translation, functional grammar. 


\section{GİRIŞ}

Filoloji bölümlerinde öğrenim görmeye başlayan öğrenciler çoğu zaman dili "kelimelerden oluşan iletişim sistemi" biçiminde tanımlamaktadırlar ${ }^{1}$. Öğrenciler tarafından dil, yapı ve anlam bütünlüğü olarak düşünülmemekte, dil dizgesindeki yapıların işlevleri sorgulanmamaktadır. Öğrencilerin kendi ana dillerini yapısal ve anlamsal boyutu olan dizge olarak görmemeleri yabancı dil/çeviri eğitimi açısından sorun oluşturmaktadır. Ayrıca öğrencinin bu bakış açısı, çeviri sürecinin ilk aşaması olan ve biçimlerin arkasında bulunan anlamsal bilgilerin çözümleme aşamasının atlanmasını ve ana dilindeki yapıların başka dil dizgesine otomatik olarak aktarılmasını tetiklemektedir. Bunun sonucunda öğrencinin ana dilinin "dünya görüşüne" (Üçok, 2004, s. 34; Vardar, 2001, s. 16; Aksan, 2009, s. 69) göre kurulmuş metinler, cümleler, öbekler ve türetilmiş sözcükler ortaya çıkabilmektedir. Öğretim sürecinde öğrencinin ana dilinin etkisiyle ortaya çıkan ve "girişim hatası" olarak tanımlanan (Öksüz, 2014) hataları önleyebilmek ve öğrenciye çeviri sürecinde iki dil dizgesi arasında yapısal ve anlamsal dönüşümleri öğretebilmek için öğrencinin ilk önce kendi ana dilinin anatomisini çözümlemesi gerektiği anlaşılmaktadır (Kozan, 2017). Ancak üniversitelerin dil bölümlerine yerleşen öğrenci, Türkçedeki yapı-işlev-anlam ilişkilerini çözümlemeye hazır olmamaktadır. Bu durum birçok araştırmacı tarafından dile getirilmektedir (Esen ve Eruz 2008, s. 69; Tarakçığlu, 2010, s. 32; Keskin, 2010, s. 244; Durukan, 2016, s. 42). Amaç, çeviri olgusunun tüm boyutlarıyla kavratılması ve çeviri sürecinin öğretilmesi ise öğrencinin dile yönelik belli bir bakış açısı geliştirmesi beklenmektedir. Ayrıca dilin, anlamsal bilgileri farklı yapılarla kodlayan bir dizge olduğu, aynı anlamsal bilgilerin farklı dillerde farklı yapılarla dile getirilebildiği, her dilin anlamsal bilgileri dile getirirken dünya görüşünü yansıttığı ve iki farklı dilin dünya görüşleri arasında ciddi farklılıkların olabildiği, bu farklılıkların hem yapısal hem de anlamsal boyutta kendisini gösterebildiğini kavratan işlevsel yaklaşım söz konusudur (Musaoğlu, 2003, s. 22; Mustayoki, 2006, s. 20; Kozan, 2016, s. 263; Kozan, 2018, s. 672). Çeviri/yabancı dil eğitimi için son derece önemli olan dile yönelik bu bakış açısının üniversitede geliştirilmesi ve öğrenciye benimsetilmesi gerektiği anlaşılmaktadır. $\mathrm{Bu}$ durumda üniversitelerin çeviri/yabancı dil eğitimi veren bölümlerinde dil dizgesinin tüm boyutlarının betimlendiği ve çözümlendiği Türkçe/Türk Dili gramer derslerinin verilmesi şarttır.

\section{Sorunlar}

Bilindiği gibi üniversitelerin yabancı dil/çeviri bölümlerinde Türkçe dil bilgisi/Türk dili dersleri birinci sınıfta verilmektedir. Ancak derslerde verilen bilgilerin, çeviri eğitiminin amaçlarının doğrultusunda dile yönelik yeni bir bakış açısını sağlayıp sağlamadığını sorgulamak gerekir. $\mathrm{Bu}$ noktada yabancı dil/çeviri bölümlerine yerleşen öğrencilerin Türkçeye yeni bakış açısı geliştirmelerini sağlayabilen başta ders kitapları olmak üzere konu ile ilgili kaynaklar sorunu karşımıza çıkmaktadır. Türkçe dil bilgisi ile ilgili ders kitapları, üniversitedeki öğretim görevlilerinin bu ders kitaplarına göre hazırladığı ders notları öğrencinin orta okuldan itibaren alışık olduğu Türkçeye yönelik yapısal bir yaklaşım sergilemektedir. Yapısal bir yaklaşım dil dizgesindeki unsurların belli sınıflandırmalara göre betimlenmesini öngörmektedir. Sınıflandırmalar arasında farklılıklar olsa bile yaklaşımın ana fikri değişmemektedir. Ayrıca dil dizgesindeki unsurların ve yapıların belli kriterlere göre tespit edilmesi ve adlandırılması söz konusudur. Yapıların arkasındaki bilgilerin ne 1 Gazi Üniversitesi ve Ankara Hacı Bayram Veli Üniversitesi Rus Dili Hazırlık Programında öğrenim görmeye
başlayan öğrencilerin dile yönelik tutumlarından yola çıarak tespit edilmiştir.

SEFAD, 2019; (41): 143-156 
olduğu, nasıl ve neye göre dil dizgesinde yapılandırıldığı gibi sorular ele alınmamaktadır. Örnek olarak başvuru ve ders kitaplarındaki -DIK yapılarına yönelik yaklaşımlar gösterilebilir.

Anadolu Üniversitesi tarafından hazırlanan "Türkçe Cümle Bilgisi-II" ders kitabında DIK yapıları sıfat-fiil konulu derste gösterilmektedir. Sıfat-fiil grubu ile ilgili şu bilgiler verilmektedir:

- “(...) sifat-fiil grubunda özne az bulunur ve iyelik ekli olur” (Doğan, 2012, s. 100).

- "Sıfat-fiil grupları yargı ifadesi taşımaz (...), cümle olarak kabul edilmez" (Doğan, 2012, s. 101).

- “(...) sıfat-fiil grubu barındıran cümleler söz diziminde yapı bakımından birleşik değil basit olarak değerlendirilmelidir" (Doğan, 2012, s. 101).

Derste gösterilen örnekler -AN/-ACAK/-MIŞ yapılarını içermektedir. -DIK yapılı cümleler örneklerde gösterilmemiştir.

Boğaziçi Üniversitesi tarafından hazırlanan "Türk Dili Ders Notları" ders kitabında DIK yapılarının örnekleri "Sıfat-Fiil (Partisip)" konulu derste gösterilmektedir. Sıfat-fiil ile ilgili şu bilgiler verilmektedir: "Başka dillerde pek bulunmayan kip çeşitliliği yanında yine bizim dilimize has sıfat-fiil ve zarf-fiiller, Türkçeyi adeta bir fiil dili haline getirmiştir. Fiillerden yapılan geçici sıfatlara sıfat-fiil (partisip) denir. (...) -dık/-dik ve -acak/-ecek çoğunlukla iyelik ekleriyle birlikte kullanılır" (Boğaziçi Üniversitesi, 2010, s. 204). Örnek olarak "Geldiği gibi gitti" cümlesi gösterilmiştir.

Gazi Üniversitesi öğrencileri için hazırlanan "Türk Dili-II" dersine ait çalışma materyallerinde -DIK yapıları üzerinde çok durulmamaktadır. -DIK yapısı sıfat-fiil grubunda gösterilmektedir. Sıfat-fiil ile ilgili şu bilgiler verilmektedir:

"Sıfat-fiil, fiil çekimine girmeyen ama aldığı eklerle fiilin zamana bağlı olarak aldığı anlamı sıfatlaştıran fiil şekline denir. (...) Sıfat-fiiller fiile getirilen -an/-asi/-maz/-ar/-dık/acak/-mış ekleriyle yapılır. Bir sıfat-fiil ile onu anlamca tamamlayan yardımcı unsurlardan oluşan kelime grubuna sıfat-fiil grubu denir. Sıfat-fiil, grubun ana unsurudur ve sonda bulunur". ${ }^{2}$ Örnek gösterilmemiştir.

L. Karahan'ın "Türkçede Söz Dizimi" adlı çalışmasında -DIK yapıları sıfat-fiil grubu olarak ele alınmaktadır:

"Grubun ana unsuru sıfat-fiildir, genellikle sonda bulunur. (...) yüklem görevi yapan sıfat-fiilin anlamı, özne, nesne, yer tamlayıcısı ve zarf adı verilen ögelerle tamamlanır. Yüklem olan sıfat-fiil yargı bildirmez. (...) Bu grupta özne az kullanılır. Özne olan unsur iyelik eki taşır. (...) Sıfat-fiil grubu söz dizimi içinde isim, sıfat ve zarf görevi yapar." (2013, s. 54).

-DIK yapısının olduğu az sayıdaki örneklerden biri "Bu eseri tamamlamak için ne kadar çabaladığını hiç kimse bilmiyordu" cümlesidir.

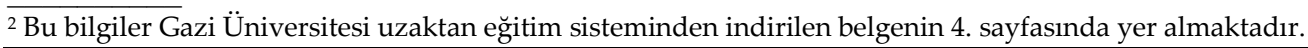


M. Özmen'in "Türkçenin Sözdizimi” adlı kitabında -DIK yapısı "-Dık/-Duk Sıfat-Fiil Grubu" olarak karşımıza çıkmaktadır. ${ }^{3}$ Bu gruba dair şu bilgiler verilmektedir: "Geçmiş zaman bildirir. Bu sıfat-fiil yaygın olarak üzerine iyelik eki alır."(2013, s. 121). Gösterilen örnekler arasında "bildiğim ve sevdiğim Erzurum", "bir-iki çevirdikten sonra", "saçlarını düzelttiği belliydi", "Cemal Paşa deniz müzesi yapmaya karar verdiği zaman” gibi öbekler var (2012, s. 122).

G. Karaağaç'ın "Türkçenin Söz Dizimi” başlıklı çalımasında -DIK yapısına dair birkaç örnek "Fiilimsi Öbekleri" bölümünün "İsim-Fiil Öbekleri (participles)" adlı alt bölümünde gösterilmektedir. Görüldüğü gibi bu çalışmada sıfat-fiil yerine isim-fiil kavramı kullanılmıştır. Bu yaklaşımın temelinde "bir isim gibi çekimlenebilir" fikri bulunmaktadır (Karaağaç, 2012, s. 168). “İsim-fiil ekleri fiillere eklenerek onları isimleştirirler. İsim-fiillik, bir yapma veya olma adının, bir olay adının, kısacası bir cümlenin isim olarak kullanımından ibarettir. (...) -dık isim-fiili iyelikli bir kullanıma sahiptir." (Karaağaç, 2012, s. 170). Bu bağlamda -DIK yapısı için üç örnek verilmektedir: "Benim gördüğüm Ali"nin babasıymış.", "Senin bildiğin bir şey yok.", "Bana sunduğu saygıyı kimse sunmaz.".

Görüldüğü gibi incelenen kaynaklardaki yaklaşım -DIK yapılarına yönelik biçimsel bir bakış açısı sunmaktadır. Ayrıca -DIK yapısı olan birimler "sıfat-fiil", "fiilimsi", "isimfiil", "isimsiler", "isimlikler" olarak adlandırılmaktadır. Bu sinıflandırmanın temelinde yapının biçimsel (eklerin niteliği, bir dilbilgisel kategoriden (fiil) türetme) özelliklerinin bulunduğu anlaşılmaktadır. Ancak bu biçimsel sınıflandırma bu yapıların kullanımlarını ve yapıların arkasındaki bilgileri açıklamamaktadır. Bu yaklaşımdan yola çıkarak öğrenci aşağıdaki cümlelerde "sıfat-fiil" kategorisini görmekte, ancak cümle (ve dil dizgesi) içindeki -DIK yapısının işlevini görmemektedir:

1. Arkadaşımın okudŭ̆u kitabı ben de okumak istiyorum.

2. Arkadaşımın bu haberi okuduğunu bilmiyordum.

3. Arkadaşım kitap okuduğu zaman hiçbir şey duymuyor.

Öğrenci -DIK yapısının kodladığı bilgileri görmediği için 1., 2. ve 3. cümlede -DIK yapısının yeri (birinci cümlede "arkadaşımın okuduğu kitap" ("arkadaşımın kitap okuduğu" değil); ikinci cümlede "arkadaşımın bu haberi okuduğu" ("arkadaşımın okuduğu bu haberi" değil)) ve kullanımı (üçüncü cümlede öznenin iyelik eklerini almaması durumu) anlaşılmamaktadır. Bunun yanı sıra yukarıdaki kaynaklarda yapıların işlevlerinin açıklanması yerine didaktik bir yaklaşım görülebilir. Örneğin, “-dık çoğunlukla iyelik ekleriyle kullanılır." (Türk Dili Ders Notları, 2010/204) "kural"ına şu sorular yöneltilebilir: Neden bu yapılar iyelik ekleriyle kullanılır? Burada iyelik eki nasıl bir işlev üstlenir? İyelik eki ne zaman kullanılmaz? Neden kullanılmaz? Benzer bir şekilde yukarıda gösterilen ve kural niteliğinde olan yargılar şu şekilde sorgulanabilir:

"Yüklem olan sıfat-fiil yargı bildirmez. Bu grupta özne az kullanılır. Özne olan unsur iyelik eki taşır." (Karahan, 2013, s. 54) - Özne neden az kullanılır? Yarg1 bildirmiyorsa neden bu yapının çözümlenmesinde cümle çözümlenmesindeki (özne-yüklem) kavramlar kullanılmaktadır?

"Geçmiş zaman bildirir." (Özmen, 2013, s. 121) - Bu yapılar her zaman mı geçmiş zaman bildirir? Bu durumda "İki ülkenin de demokratik çok kutuplu dünyanın oluşumu için

${ }^{3}$ Kitabın “Cümle ve Cümlenin Ögeleri” başlıklı bölümünde -DIK- yapıları 'isimsiler veya isimlikler' olarak karşımıza çıkmaktadır (Özmen, 2012, s. 37).

SEFAD, 2019; (41): 143-156 
çalıştığına işaret eden Rusya lideri, uluslararası hukuk ve tüm ülkelerin çıarlarının korunduğu bir yapının önemine dikkat çekti" cümlesindeki -DIK yapılarının kullanımı nasıl yorumlanabilir?

"Sıfat-fiil grubu cümle olarak kabul edilmez." (Türkçe Cümle Bilgisi-II, 2012/101) Sıfat-fiil grubu cümle olarak neden kabul edilmez? Yapısal ve işlevsel dil bilgisinde cümleye yönelik farklı yaklaşımların sergilendiğini hatırlarsak cümle, tanımına göre değişen bir kavram değil midir? ${ }^{4}$

"Sıfat-fiil grubu barındıran cümleler söz diziminde yapı bakımından birleşik değil basit olarak değerlendirilmelidir." (Türkçe Cümle Bilgisi-II, 2012/101) - Bu yapı neden basit olarak kabul edilmeli? Basit ve birleşik cümle tanımına bağlı bir çıkarım değil midir?

İncelemenin sonucunda kaynaklarda -DIK yapıları üzerinde çok az durulduğu anlaşılmaktadır. Ancak bu yapılar medya ve siyasi söylemin ayrılmaz bir parçasıdır. Gazete, haber ajansının web-sayfası, Cumhurbaşkanlığı ya da Dışişleri Bakanlığı tarafından yapılan basın açıklamaları, siyasetçilerin konuşmalarını incelediğimizde -DIK yapılarının Türkçenin dizgesinde çok önemli bir işlev üstlendiği, farklı bilgi paketlerinin aynı birimle (cümle) sunulmasına fırsat verdiği anlaşılmaktadır. Aşağıdaki cümleler bu fikri doğrulamaktadır:

Çavuşoğlu görüşmenin ardından yaptı̆̆ı açıklamada, ABD ile yol haritasını onayladıklarını (...) söyledi. ${ }^{5}$

Körfez uzmanı araştırmacı Nuha Ebu ed-Deheb, bir yıl geçmesinin ardından Katar'a yönelik Suudi Arabistan'ın yönettiği ve ABD'nin desteklediği ambargonun, büyük bir yapbozun parçası olduğunun netleştiğini ifade eti. 6

Demokrasiyle bağdaşmayan bu düzenlemeyle mutabık olmadığımız (...) ancak, getirilen yasağın tüm siyasi partiler için ayrım gözetilmeden uygulanmasın beklediğimiz Alman makamlarına bildirilmişti. ${ }^{7}$

Yabancı dil/mütercim-tercümanlık bölümünde okuyan öğrencinin, -DIK yapılarının yanı sıra diğer yapıları içeren bu tür metinleri anlayıp çözümlemesi ve başka dile çevirebilmesi beklenmektedir. Ancak bu metinlerin oluşturulduğu yapıların işlevsel betimlenmesinin ve çözümlenmesinin yer verildiği kaynakların olmaması, yabancı dil/çeviri eğitimi açısından sorun oluşturmaktadır. Konu ile ilgili eleştiri "Türkçede Niteleme. Sıfat İşlevli Yan Tümceler" başlıklı çalışmada F. Akerson ve S. Şeyda Özil (2015, s. 17) tarafından dile getirilmektedir:

“(...) 1950 ve 1960”lı yıllarda Türkçeyi çözümleyen geniş kapsamlı dilbilgisi kitapları yayımlanmıştır. Ancak bunlar yazıldıkları dönemlerdeki dilbilgisi anlayışı doğrultusunda geleneksel yöntemlerle hazırlanmıştır ve bugün hâlâ temel başvuru kitapları olarak kullanılmaktadır. (...) yeni dilbilgisi kitapları yayımlanmaktadır. Ama bunların Türkçe dilbilgisinin incelenmesi açısından öncekilerden pek de farkları yoktur. Bu kitaplar yeni dilbilgisi yöntemleriyle değil, geleneksel yöntemlere bağlı kalınarak hazırlanmıştır. Çeşitli aralıklarla yayımlanan ders kitaplarmın temelini de bu dilbilgisi kitapları oluşturur.

\footnotetext{
${ }_{4}$ Cümle kavramı ile ilgili görüş ve tanımlara C. Kerimoğlu'nun “Türkiye Türkçesi ve Tatar Türkçesinin Karşılaştırmalı Söz Dizimi" çalışmasında geniş yer verilmiştir (2014, s. 149).

${ }^{5}$ https://tr.sputniknews.com/turkiye/201806051033729469-mevlut-cavusoglu-abd-menbic/ [06.08.2018]

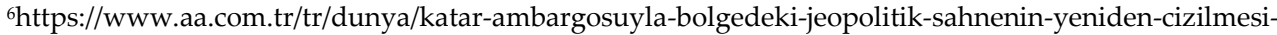
hedefleniyor/1167179 [06.08.2018]

7 http://www.mfa.gov.tr/no_-148_-almanyanin-koln-kentinde-ulkemizden-bir-siyasi-parti-tarafindan-duzenlenensecim-mitingi-hk.tr.mfa [06.08.2018]
} 
Başka bir deyişle, yeni bilimsel araştırmaların sonuçları ders kitaplarına yeterince yansimamaktadır".

\section{Çözüm(leme)}

Bu durumda çeviri/filoloji eğitiminde kullanılacak ve yapı ile anlam boyutlarını birleştiren işlevsel Türkçe dil bilgisinin hazırlanması öncelik olarak karşımıza çıkmaktadır. Türkçeye yönelik işlevsel dil bilgisi ${ }^{8}$ çerçevesinde betimlemelerin geliştirilmesi gerektiğine dair fikirler Türk dilbilimcilerin çalışmalarında dile getirilse de halihazırda bu yaklaşımı sergileyen çalışma sayısı yok denecek kadar azdır (Schaaik, 1998; Musaoğlu, 2003; Ercan ve Bakırlı, 2009; Sebzecioğlu, 2011; Selçuk, 2013). Yabancı dil öğretiminde yapısal ya da biçimsel dil bilgisinin "biçimden anlama doğru yaklaşımı sergileyen yöntemi uyguladığı için tek başına yeterli olmadığına" dair fikirler son yıllarda dile getirilmeye başlamıştır (Dalkılıç, 2017, s. 254).

İşlevsel dil bilgisi biçim-anlam ya da dil-gerçeklik arasındaki ilişkileri betimlemeyi ve çözümlemeyi amaçlamaktadır (Mustayoki, 2006, s. 21). Bunun için hem anlamla ilişkili mantık alanına özgü olan kategoriler hem de dil ile ilgili dilbilgisel kategorilere başvurulmakta ve gerçek-dil arasındaki ilişkiler belirlenmektedir. Ancak bir dilin dizgesinin özellikleri başka bir dil dizgesine göre kendisini göstermektedir. Bu noktada işlevsel dil bilgisinin, dil çiftine yönelik karşılaştırmalı çözümlemeye başvurduğu vurgulanmalıdır.

İşlevsel dil bilgisi çevirinin doğasını yansıtmaktadır. Kanımızca çeviri süreci aşağıda gösterdiğimiz "üçgen" imgesi ile açıklanabilir:

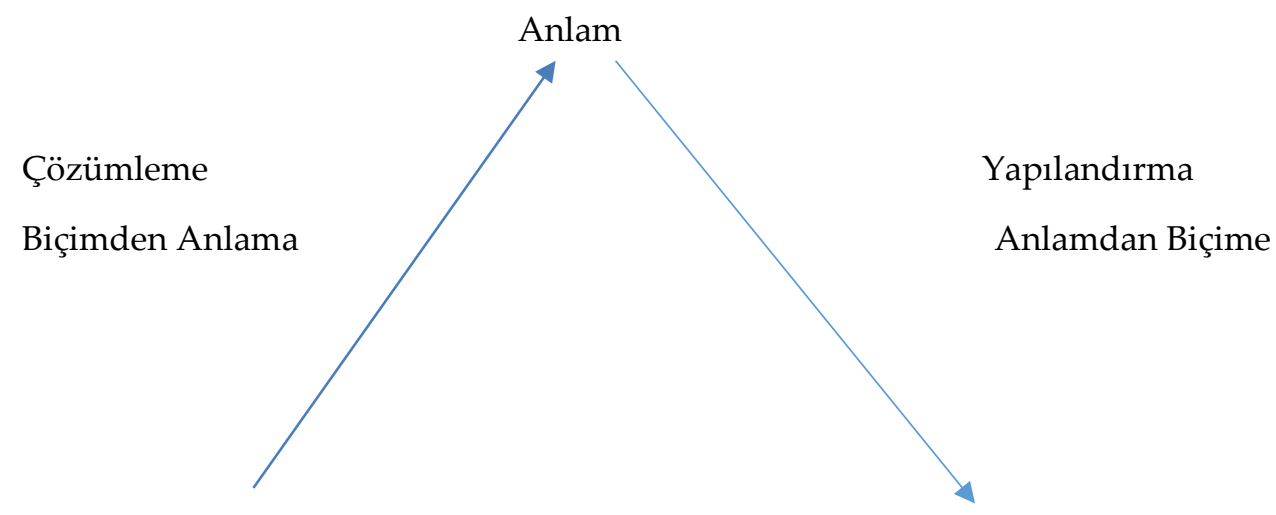

Kaynak Dil

Hedef Dil

Üçgendeki ilişkiler çeviri sürecinin, kaynak dildeki metin/cümle/öbek/sözcük/biçimbirimi ya da sesbirimi biçiminde kodlanan nesnel gerçekliğe dair bilgilerin çözümlenmesinden başladığını göstermektedir. Çeviri sürecinin bu aşamasının dilbilimsel çözümleme ile ilgili olduğu anlaşılmaktadır. Kaynak dildeki iletiyi anlayabilmek için iletinin kodlandığı biçimleri çözümlemek gerekir. Bu aşamada sürecin biçimden anlama doğru gerçekleştiği söylenebilir. Çözümlemenin sonucunda "anlam" olarak nitelenen mantık kategorileri ve arasındaki ilişkiler karşımıza çıkmaktadır. Mantık kategorilerinin ve ilişkilerin hedef dile aktarılması gerekir. Bu noktada çeviri sürecinin ikinci

8 İşlevsel dil bilgisi kuramı ile ilgili bilgiler Schaaik Van Gerdien'in (1998), M. Musaoğlu'nun (2003), O. Kozan'ın (2016) çalışmalarında bulunabilir.

SEFAD, 2019; (41): 143-156 
aşaması başlamaktadır. Çeviri sürecinin ikinci aşamasında ortaya çıkan anlamın tekrar "biçimlendirilme"si gerçekleşmektedir. Bu sefer anlamın hedef dildeki yapılarla kodlanmasından söz edilebilir. Başka bir deyişle sürecin anlamdan biçime doğru gerçekleştiği görülebilir. Çeviri sürecinin bu aşaması yapılandırma olarak düşünülebilir.

Yukarıda gösterilen cümleler işlevsel yaklaşım çerçevesinde ele alınırsa şu şekilde betimlenebilir:

1). Arkadaşımın okuduğu kitabı ben de okumak istiyorum.

Bu cümlenin dile getirildiği biçimlerin arkasında biri dilbilgisel boyutta yalın haliyle kendisini gösteren ve aktif görünen ("ben"), diğeri -IN hali ile dile yansıtılan ve pasif sayılabilen ("arkadaşımın") olmak üzere iki eylemci ortaya çıkmaktadır. Aktif eylemcinin bulunduğu iki eylem ("istiyorum", "okumak") görünmektedir. Eylemlerden biri aktif biçimlerle dile getirilmiş (zaman göstergesi (-yor), şahıs eki (-um)), diğeri ise eylemi adlandıran infinitif biçimi ile kodlanmıştır. Pasif eylemcinin bulunduğu bir eylem ("okumak") dilsel boyutta pasif biçimle (-dık) dile getirilmiş ve pasif eylem niteliğinde olarak değerlendirilebilir ("oku-duk-u"). Görüldügü gibi yukarıdaki Türkçe cümle eylemcieylem bağlamında iki olayı kodlamaktadır: "arkadaşım-okumak" ve "ben-istemekokumak". Aktif eylemcinin ve aktif eylemin oluşturduğu olayda nesne ("kitap") görülebilir. Pasif eylemcinin ve eylemin dahil olduğu pasif olayın, aktif olaydaki nesne ile ilgili ek bilgi paketini verdiği anlaşılmaktadır. Ayrıca, "kitap $\rightarrow$ arkadaşımın okuduğu kitap" biçiminde bilgi paketinin genişletilmesi söz konusudur. Bu iki olayın Türkçenin dizgesinde pasif olaydan aktif olaya doğru yapılandırıldığı görülebilir. Başka bir deyişle Türkçede ek bilgi paketlerinin ön plana çıktığı anlaşılmaktadır. Bu cümlenin, mantık ve dil kategorilerinin birleştiği formülü şu şekilde düşünülebilir:

$($ Aktif Eylemci $)+\left[\right.$ Pasif Eylemci ${ }^{\mathrm{IN}}+$ Pasif Eylem $\left.{ }^{\mathrm{DIK}}\right]+$ Nesne $^{\mathrm{I}}+$ Eylem $^{\text {Kök Biçim }}+$ Aktif Eylem ZAMAN+\$̧AHIS.

Aşağıdaki cümlenin işlevsel çözümlenmesini yapacak olursak, dilsel boyutta aynı görünen biçimlerin farklı bir olay kodladığını görürüz.

\section{2). Arkadaşımın bu haberi okuduğunu bilmiyordum.}

Cümle, biri pasif (“arkadaşımın”) biri aktif ("ben”) olmak üzere iki eylemciyi kodlamaktadır. Aktif eylemcinin bulunduğu eylem aktif biçimle dile getirilmiştir ("bilmiyordum"). Pasif eylemcinin bulunduğu eylem dilsel boyutta fiilden türetilmiş, böylece de pasif olarak sayılabilen bir biçimle dile getirilmiştir ("oku-duk-u"). Cümlede iki olayın kodlandığı görülebilir: "arkadaşım - okumak" ve "ben - bilmemek". Cümlede pasif olayın aktif olayın içinde yer aldığı ve nesne niteliğinde olduğu görülebilir. Pasif olayın, aktif olayın içindeki nesne ile ilgili ek bilgi paketini sunduğu yukarıdaki cümle ile karşılaştırırsak, bu cümlede pasif olayın aktif olay açısından nesne niteliğinde olduğu anlaşılmaktadır. Olayın nesne niteliğinde olması dilsel boyutta kendisini göstermektedir: “arkadaş-ım-ın oku-duk-u-n-U”. Bu cümlenin, mantık ve dil kategorilerinin birleştiği formülü şu şekilde düşünülebilir:

$($ Aktif Eylemci $)+\left[\text { Pasif Eylemci }{ }^{\mathrm{IN}}+\text { Pasif Eylem }{ }^{\mathrm{DIK}}\right]^{\mathrm{I}}+$ Aktif EylemªMAN + SAHIS

Bu iki cümlenin Rusça yapılandırılmasına baktığımızda aynı mantık olaylarının dilsel boyutta kendisini farklı dilsel biçimlerle dile getirilebildiği anlaşılmaktadır. 
1). Я хочу прочитать книгу, которую читает/прочитал мой друг (Sözсй̈̆̈̈ sözcü̆̆̈̈пе: ben-istiyorum-okumak-kitabı-[niteleme bă̆lacı]Belirtme Durumu_okuyor/okudu-benim-arkadaş).

2). Я не знал, что мой друг читает/прочитал эту новость (Sözсӥ̆̆̈̈ sözcӥ̆̆̈̈пе: benolumsuz parçacık-biliyordum- [açıklama bă̆lacı]- benim-arkadaş-okuyor/okudu-bu Belirme Durumu_ haberi).

Rusçada aktif olayın daima ön plana çıktığı anlaşılmaktadır. Eylemcinin ve eylemin pasif olması dilsel boyutta kendisini göstermemektedir. Başka bir deyişle, Türkçenin dizgesi açısından pasif sayılabilen eylemci ve eylem Rusçada aktif biçimlerle kendisini göstermektedir (eylemci isim halini almamakta, eylemcinin bulunduğu eylem çekimli fiil ile dile getirilmektedir). Bunun dişında Rusçada olaylar arasındaki ilişkiler, Türkçede olduğu gibi fiilden türetilmiş -DIK biçimi ile değil, niteleme/açıklama gibi işlevleri olan birimlerle dile getirilmektedir. Ayrıca, (1) cümlede "которую” biçiminde niteleme işlevli bir birim karşımıza çıkmaktadır. Bu birimin dinleyiciyi ek bilgi paketine hazırladı̆̆ı söylenebilir. Rusçadaki (1) cümlenin formülünü yazacak olursak Türkçedekinden farklı olacağ1 tahmin edilebilir. Ayrıca,

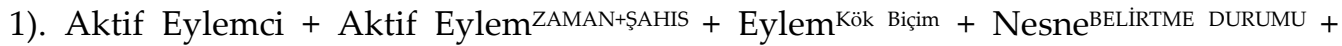
Niteleme İşlevli Ek Bilgi ÖncesisIFAT+NESNE CinsiYetí AD DURUMU + Pasif EylemZAMAN+\$̧AHIS + Pasif Eylemci ${ }^{\text {YALIN HALI. }}$

Ana dili Türkçe olan öğrenci açısından (1) cümle modeli Türkçeden Rusçaya yapılandırma aşamasında birkaç açıdan sorun oluşturabilir. Olayların farklı dizilişi yanı sıra Türkçedeki -DIK yapısının çok işlevliliği söz konusudur. Bir taraftan Türkçedeki fiilden türetme niteliğinde olan ve böylece aktif biçim olan fiil gibi davranamayan -DIK yapısının, olayın gerçekleştiği zamana yönelik genelleme yaptığı anlaşılmaktadır. Başka bir deyişle "arkadaşımın okuduğu kitap" olayındaki -DIK yapısı "arkadaşımın hâlâ okuduğu ve bitirmediği" ya da "arkadaşımın okuyup bitirdiği" zaman boyutlarını aktarabilmektedir. Rusçada pasif eylemin fiil ile dile getirildiği için ve Rusçadaki fiil kategorisinde görünüş olduğundan olayın gerçeklikte nasıl gerçekleştiğini sürekli takip etmek gerekir. Diğer taraftan Türkçedeki -DIK yapısının tek zamana karşı değil, mekânsal ilişkilere yönelik de genelleme yaptı̆̆ı anlaşılmaktadır. Ayrıca, Türkçede mantık ilişkileri açısından farklı olayların dile getirilişinde genelleyen -DIK yapısı kullanılmaktadır. Rusçada ise bağlaç olarak değerlendirilebilen niteleme işlevli birim, mantıksal ilişkilerin somutlaştırılmasını amaçlamaktadır. Aşağıdaki örneklerde bu durum gözlemlenebilir:

Arkadaşımın okuduğu kitabı ben de okumak istiyorum. $\rightarrow$ Я maкже хочу прочитать книгу, которую прочитал мой друг.

Geçen sene gittiğim ülkeye tekrar gitmek istiyorum. $\rightarrow$ Я хочу ещё раз nоехать в страну, в которую я ездил в прошлом году.

Ви yazarın doğduğu şehri görmek istiyorum. $\rightarrow$ Я хочу увидеть город, в котором родился этот nuсатель.

Uçakta tanıştı̆̆ım gazeteci tüm dünyayı gezmiştir. $\rightarrow$ Жyрналист, c которьıм я познакомился в самолёте, объездил весь мир.

Yazarın anlattı̆̆ı olaylar XIX. yüzyılda meydana gelmiştir. $\rightarrow$ Собъıтия, o кomopbıx рассказывает писатель, произошли в XIX веке.

SEFAD, 2019; (41): 143-156 
Yukarıdaki örneklerde Türkçedeki -DIK yapısının, birkaç mantıksal olayı birleştirebilen cümlede eylemci ya da nesne ile ilgili ek bilgilerin sunulabildiği modellerden biri olduğu görülebilir. -DIK yapısı mantık açısından farklı eylemci-eylem-nesne ilişkilerini dilsel boyutta genellemektedir. Ayrıca, "arkadaşımın okuduğu kitap" $\rightarrow$ "arkadaş-ım+ kitab-1+ okumak", "gittiğim ülke" $\rightarrow$ "ben+ ülke-ye + gitmek", "yazarın doğduğu şehir" $\rightarrow$ "yazar + şehir-de + doğmak", "tanıştığım gazeteci" $\rightarrow$ "ben + gazeteci + ile + tanışmak", "yazarın anlattığı olaylar" $\rightarrow$ "yazar + olaylar-1 + anlatmak". Rusçada eylemci-eylem-nesne arasındaki mantıksal ilişkiler dilsel boyutta somutlaştırılmaktadır. Tüm mekânsal ilişkiler niteleme amaçlı birimin çekiminde ve yanına gelen edatlarda kendisini göstermektedir. Ayrıса "книга, которую прочитал мой друг" $\rightarrow$ eylemci-nesne ilişkisi-nesnenin belirtilmesi (arkadaşım kitabı okudu); “страна, в которую я ездил" $\rightarrow$ eylemci-mekân ilişkisi-yönelme (ülkeye gittim); “город, в котором родился писатель” $\rightarrow$ eylemci- mekân ilişkisi-bulunma (yazar şehirde doğdu); "журналист, с которым я познакомился" $\rightarrow$ eylemci - eylemci ilişkisi-birliktelik (gazeteci ile tanıştım); “события, о которых рассказывает писатель" $\rightarrow$ eylemci-nesne ilişkisi - konuşma nesnesi (yazar olaylar hakkında anlattı). Böylece Türkçe-Rusça dil çiftinde çalışan çevirmenin çeviri sürecinde sürekli karşılacağı işleminin, Türkçedeki genelleyen -DIK yapılarının Rusçada somutlaştırılması olduğu anlaşılmaktadır.

Türkçedeki -DIK biçiminin yukarıda gösterilen niteleme işlevinin yanı sıra açıklama işlevinin de olduğu anlaşılmaktadır. Türkçedeki (2) cümlede -DIK yapısı karşımıza çıkmaktadır. Ancak bu bağlamda yapının niteleme işlevli olmadığı görülebilir: (2) cümlenin işlevsel boyutunda iki olay birbirine açılama ilişkisi ile bağlıdır. Bu durumda Rusçada da durum değişmekte ve olayları ilişkilendirmek için açıklama işlevli birim ("что") karşımıza çıkmaktadır: "Arkadaşımın bu haberi okuduğunu bilmiyordum" $\rightarrow$ "Я не знал, что мой друг читает/прочитал эту новость". Rusçadaki bu cümlenin işlevsel ve yapısal boyutunun birleştiği formül bu şekilde yazılabilir:

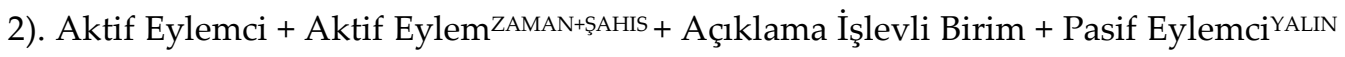
HALI + Pasif Eylem ZAMAN+\$̧AHIS + Nesne.

Yukarıdaki örneklerden yola çıkarak Türkçenin ve Rusçanın mantık kategorilerinin dile getirilmesi sırasında farklı davrandığı anlaşılmaktadır. Yukarıda belirlenen formüllere baktığımız zaman Türkçenin, birbirine bağlı olayları dile getirirken yan olaydan başladığı, yan olaydaki eylemciyi ve eylemcinin bulunduğu eylemi dilsel boyutta "pasifleştirdiği", pasifleştirmenin en yaygın modeli olarak ise, eylemcinin dilsel biçiminde -(N)IN ekini, eylemin dilsel biçiminde -DIK yapısını kullandığı görülebilir. Türkçeye yönelik bu bakış açısı, öğrencinin dilsel biçimleri ile anlamsal kategorileri bütünlük içinde görmesini sağlamaktadır. Ya da başka bir deyişle her alanda karşımıza çıkan biçim-anlam ikilemesinin kavranmasını tetiklemektedir. Bunun yanı sıra çeviri eğitiminin ilk aşamasında gösterilen bu yaklaşım, dillerin anlamsal bilgi kodlama modellerinin kavranmasına ve böylece çeviri sürecinde çok önemli olan "model tahmin edebilirliği" kavramının benimsetilmesine yardımcı olmaktadır. Ayrıca, işlevsel yaklaşımın sağladığı bakış açısı öğrenciyi yukarıda bahsedilen medya söyleminde kullanılan modellerin yabancı dilde yapılandırma aşamasına hazırlamaktadır. Böylece aşağıdaki ilk bakışta karmaşık gibi görünen cümlenin yapısal boyutunun yapılandırılması tahmin edilebilir: 
Çavuşoğlu görüşmenin ardından yaptığı açıklamada, ABD ile yol haritasımı onayladıklarını (...) söyledi. $\rightarrow$ Чавушоглу, в заявлении, которое он сделал/сделанном после встречи, объявил, что по вопросу «дорожной картыъ» с США было достигнуто понимание. ${ }^{9}$

Görüldüğü gibi karşılaştırmalı işlevsel yaklaşım dile, yapısal ve anlamsal boyutların bütünlük içinde ele alındığı bir bakış açısı sunmaktadır. Bu bütünlügün algılanması çeviri sürecinde son derece önemlidir. Çeviri eğitiminin ilk aşamasından itibaren öğrencinin ana diline yönelik işlevsel yaklaşımı benimsemesi, kendi dilinin mantığının ve dünya görüşünün kavranmasını sağlayacaktır.

\section{SONUÇ}

Çeviri eğitiminde öğrencinin dile yönelik belli bir yaklaşımı benimsemesi amaçlanmaktadır. Bu yaklaşım insana özgü olan ve böylece evrensel sayılabilen mantık kategorilerinin farklı dillerde farklı biçimlerle kendisini gösterebildiğini vurgulamaktadır. Başka bir deyişle her dilin kendine özgü dünya görüşü vardır. Dilin bu dünya görüşü tarih boyunca şekillenmekte ve iki dilin eş zamanlı karşılaştırılmasında görünür hale gelmektedir. Böylece öğrencinin başka bir dilin dünya görüşünü kavramasının, ana dilinin dünya görüşünün çözümlenmesine ve kavranmasına bağlı olduğu söylenebilir. Bu durumda öğrencinin ana dilinin betimlendiği "dil bilgisi" nin önemi karşımıza çıkmaktadır.

Türkçenin dizgesinin betimlendiği nice ayrıntılı çalı̧̧maların olmasına rağmen çeviri eğitiminde kullanılabilecek ya da başka bir deyişle çevirmenler için hazırlanmış betimlemeler bulunmamaktadır. Çeviri eğitimini gören öğrenci Türkçenin yapısal boyutunun ele elındığı geleneksel dil bilgisi ile karşılaşmaktadır. Ancak Türkçenin geleneksel betimlemelerinde yapısal boyut ön plana çıkmakta, yapının arkasındaki mantık kategorileri ya da başka bir deyişle yapının işlevsel boyutu ise ele alınmamaktadır. Yukarıda bu durum Türkçedeki -DIK yapılarının ders kitaplarındaki betimleme örnekleri ile gösterilmiştir. Çeviri eğitiminde bu betimlemelerin olmamasının bir eksiklik olduğu anlaşılmaktadır. Böylec, yabancı dil/çeviri eğitimi için işlevsel Türkçe dil bilgisinin hazırlanması öncelik olarak karşımıza çıkmaktadır. Bu dil bilgisinin yapı ve anlam boyutlarını birleştirmesi beklenmektedir. Yapı ve anlam boyutlarının birleştirilmesi ise yukarıda gösterildiği gibi çeviri sürecinin doğasını yansıtmaktadır.

Bu çalışmada işlevsel yaklaşımın örneği olarak Türkçedeki -DIK yapıları ele alınmıştır. Türkçedeki -DIK yapısının dil dizgesinde çok işlevli olduğu belirlenmiştir. Ayrıca -DIK yapılarının cümlede mantıksal olayların birleştirilmesinde ortaya çıtığı, hem niteleme hem de açıklama işlevlerinin olduğu ve genelleyen yapılar niteliğinde olduğu tespit edilmiştir. Türkçedeki -DIK yapılarının arkasındaki mantıksal kategorilerin Rusçanın dizgesinde farklı birimlerle dile getirildiği gösterilmiştir. Karşılaştırma sırasında elde edilen bilgiler Türkçe-Rusça dil çiftindeki çeviri sürecinin kavratılması açısından önem taşımaktadır. İlk önce çeviri sürecinde çözümleme aşamasının vazgeçilmez bir aşama olduğu anlaşılmaktadır. Türkçedeki -DIK yapılarının arkasındaki mantık kategorileri belirlenmeden çeviri sürecinin ikinci aşaması olan yapılandırmanın mümkün olmadığ görülebilir. Türkçenin dil bilgisine yönelik işlevsel yaklaşımın geliştirilmesinin yabancı

\footnotetext{
${ }_{9}$ Burada verilen, çeviri seçeneğidir. Ayrıca, bu çalışmada Türkçe-Rusça çeviri sürecindeki yapısal dönüşümlere öncelik verilmiştir. Anlamsal dönüşümler ('yol haritası onaylandı' $\rightarrow$ 'дорожная карта' была одобрена/было достигнуто понимание по 'дорожной карте'/была принята 'дорожная карта') bu çalışmanın kapsam dişında kalmiştır.
}

SEFAD, 2019; (41): 143-156 
dil/çeviri eğitimi açısından son derece önemli olduğu söylenebilir. Bunun yanı sıra Türkçenin dizgesinin gerek yapı gerekse yapının arkasındaki mantık kategorileri açısından betimlendiği işlevsel yaklaşım, felsefeden çeviribilime kadar her alanda karşımıza çıkan biçim-anlam ikilemesini kavramamızı ve çözümlememizi sağlayabileceği de anlaşılmaktadır.

\section{SUMMARY}

The article deals with the problems during the translation process caused by the structural approach to Turkish language adopted by the students of translation, with Turkish being their native language. It also highlights the necessity to develop a functional approach to Turkish in translation teaching alongside the traditional grammar books with a structural paradigm. The structural approach to Turkish adopted by the students since elementary school is seen to be a triggering factor behind the words, phrases, sentences and texts derived according to the "logic" of Turkish language during the translation into the target language. In that case, the first task of the translation training is to make a student develop a wider perspective on the language. This perspective enables us to see the language as a system, coding semantic information in various structures. The same semantic information can be externalized in different structures of the different languages. The core idea of the approach is that every language reflects its own worldview while coding semantic information in structures. Thus, the problem of university coursebooks on Turkish as well as other sources on the subject used by the students of translation or foreign languages is to be discussed.

It was found out that university coursebooks on Turkish are based on structural approach to the language. The structural approach implies the description of all components of the language system according to some structural criteria. Although there are different claasifications of the components, the main idea is the same. This approach reveals the physiology of the language without going into details about functioning of the organs. The coursebooks do not raise the issue of semantic information behind the structures. Thus, the questions of how and according to what this information is encoded remain unanswered.

The study shows that there is a necessity to apply a functional approach to description of Turkish within the context of translation training. The functional approach aims at defining and analyzing the relations between the structure and the meaning. For this purpose, semantic categories applied in logics as well as grammatical categories are introduced. These categories are to define the relations between the reality and the language. But the distinctive features of one language system can be seen while in contrast with another one. Thus, the functional approach implies a contrastive analysis of the language pair.

The article reveals the problems encountered during the translation training/ foreign language learning by the native Turkish students who try to apply the traditional Turkish grammar, focusing on structural level of the language, with examples given for the TurkishRussian language pair. The main focus of the article are the -DIK structures known as "sifatfiil" in Turkish grammar that can cause problems in Turkish-Russian translation process. The functional analysis of the -DIK structures reveals that Turkish and Russian act differently when externalizing the semantic categories. Turkish, in contrast to Russian, puts forward a secondary event, makes participant and its action in the secondary event look 
"passive" on the language level and apllies -(N)IN affix to the participant and -DIK affix to its action as a mean to show their passiveness. For example,

Arkadaşımın okuduğu kitabı ben de okumak istiyorum $\rightarrow$ Я также хочу прочитать книгу, которую читает/nрочитал мой дpyz. (I also want to read the book (that) my friend is reading/has read).

TUR: (Active Agent) $+\left[\right.$ Passive Agent ${ }^{\mathrm{IN}}+$ Passive Action $\left.^{\mathrm{DIK}}\right]+$ Object $^{\mathrm{I}}+$ Action $^{\text {Infinitive }}+$ Active Action ${ }^{\text {Tense+Person }} \rightarrow$

RUS: Active Agent + Active Action ${ }^{\text {Tense+Person }}+$ Action $^{\text {Infinitive }}+$ Object $^{\text {Accusative }}+$ Explicative Conjunction ${ }^{\text {Adjective+ Gender+ Case }}+\left[\right.$ Passive Action ${ }^{\text {Tense+Person }}+$ Passive Agent $\left.{ }^{\text {Nominative }}\right]$.

-DIK structures in Turkish are notable for their multifunctionality. On the one hand, these passive structure do not act like the verbs which can be named as active forms since they externalize semantic information about the action explicitly. -DIK structures, being verb derivatives, seem to generalise the time of the action. Thus, -DIK structure in "arkadaşımın okuduğu kitap" may refer to "arkadaşımın hâlâ okuduğu ve bitirmediği" as well as to "arkadaşımın okuyup bitirdiği" event. On the other hand, -DIK structures in Turkish seem to generalise not only the time of the action but space ralations between the participant, his action and object of the action. Thus, events which seem to be different from a logical perspective have the same structural model on the language level. In contrast to Turkish, Russian tends to specificate different logical relations as shown in the following examples:

Arkadaşımın okuduğu kitabı ben de okumak istiyorum. $\rightarrow$ Я также хочу прочитать книгу, которую прочитал мой друг. (I also want to read the book (that) my friend has read).

Geçen sene gittiğim ülkeye tekrar gitmek istiyorum. $\rightarrow$ Я хочу ещё раз noexamь в страну, $\boldsymbol{6}$ которую я ездих в прошлом году. (I want to visit again the country I went to last year / I want to visit the country (to) which I went last year).

Ви yazarm doğduğu şehri görmek istiyorum. $\rightarrow$ Я хочу увидеть город, в котором poдuлcs эmom nucamesb. (I want to see the city this writer was born in / I want to see the city where (in which) this writer was born).

Uçakta tanıştığım gazeteci tüm dünyayı gezmiştir. $\rightarrow$ Журналист, с которым $\boldsymbol{я}$ познакомился в самолёте, объездил весь мир. (The journalist I met with in the airplane (during the flight) travelled all over the world / The journalist with whom I met in the airplane (during the flight) travelled all over the world).

Yazarın anlattığı olaylar XIX. yüzyılda meydana gelmiştir. $\rightarrow$ События, о которых pассказывает писатель, произошли в XIX веке. (The events the writer is talking about took place in the XIXth century / The events about which the writer is talking took place in the XIXth century).

In conclusion, it can be said that the functional approach helps a student to see the language structures and the semantic categories in their continuity. This approach, if given at the very beginning of the translation training, helps the student to realize the coding models of semantic information in different languages and to apply these models during the translation process to the target language. 


\section{KAYNAKÇA}

Akerson, F. E. ve Özil, Ş. (2015). Türkçede niteleme. Sıfat işlevli yan tümceler. Ankara: Türk Dil Kurumu Yayınları.

Aksan, D. (2009). Anlambilim. Anlambilim konuları ve Türkçenin anlambilimi. Ankara: Engin Yayın Evi.

Boğaziçi Üniversitesi Türkçe Dersleri Koordinatörlüğü, (2010). Türk dili ders notları I. İstanbul: Boğaziçi Üniversitesi.

Dalkılıç, Ç. L. (2017). Priçastiye v russkom i turetskom yazıkah v sravnitelnom aspekte. Karadeniz Araştırmaları, 14(55), 253-268.

Doğan, E. (2012). Türkçe cümle bilgisi-I. Eskişehir: Anadolu Üniversitesi.

Durukan, E. (2016). Çeviri odaklı karşılaştırmalı dilbilgisinin temel çeviri becerisi edinimindeki önemi. Dil Eğitimi ve Araştırmaları Dergisi, 2(2), 41-52.

Ercan, G. S. ve Bakırlı, Ö. C. (2009). Türkçede özne belirtme ve özne yükleme: İşlevsel dilbilgisi çerçevesinde bir çalışma. Dil Dergisi, 143, 42-58.

Esen-Eruz, S. (2008). Akademik çeviri eğitimi. Çeviri amaçlı metin çözümlemesi. İstanbul: Multilingual.

Karaağaç, G. (2012). Türkçenin söz dizimi. İstanbul: Kesit Yayınları.

Karahan, L. (2013). Türkçede söz dizimi. Ankara: Akçağ Yayınları.

Kerimoğlu, C. (2014). Türkiye Türkçesi ve Tatar Türkçesinin karşılaştırmalı söz dizimi. Ankara: Türk Dil Kurumu Yayınları.

Keskin, A. (2010). Çeviribilim tartışmaları gölgesinde çeviri öğretimi ve çeviri didaktiği gereksinimi. Trakya Üniversitesi Sosyal Bilimler Dergisi, 12(2), 229-248.

Kozan, O. (2016). Yabancı dil/çeviri eğitiminde işlevsel söz dizimi kuramı. Rusça-Türkçe dil çifti örneği. A. Kaşoğlu (Ed.), Prof. Dr. Altan Aykut'a armağan. Rus dili ve edebiyatının izinde içinde. İstanbul: Çeviribilim.

Kozan, O. (2017). Yabancı dil/çeviri eğitiminde karşıtsal çözümleme: Biçim-işlev-anlam üçlüsü. Dil Dergisi, 168(2), 65-81.

Kozan, O. (2018). Bilişsel dilbilim ve yabancı dil öğretimi. Ya da... Karahindiba ile yastık arasında ortak bir şey var mı? Z. Karacagil ve E. Anaz (Ed.), Current Debates on Social Sciences 1. Human Studies içinde. Ankara: Bilgin Kültür Sanat Yayınları.

Musaoğlu, M. (2003). Türkçenin işlevsel dilbilgisi ve metin kompozisyonu. Dil Dergisi, 120, 22-40.

Mustayoki, A. (2006). Teoriya funktsional'nogo sintaksisa: Ot semantiçeskih struktur k yazıkovım sredstvam. Moskova.

Öksüz, G. (2014). Rus dili öğretiminde karşılaşılan ana dil kaynaklı girişim hataları. Turkish Studies, 9(6), 843-857.

Özmen, M. (2012). Türkçenin sözdizimi. Adana: Karahan Kitabevi.

Schaaik, van G. (1998). İşlevsel dilbilgisi nedir? Dilbilim Araştırmaları, 9-25.

Sebzecioğlu, T. (2011). Türkçede özne yükleme. Dil ve Edebiyat Dergisi, 8(1), 15-40.

Selçuk, K. (2013). İşlevsel dilbilgisi çerçevesinde Kırgızcada ettirgenliğin işlevsel-anlamsal alanı. Turkish Studies, 8(1), 2241-2256.

Tarakçıoğlu, A. Ö. (2010). Eğitim fakültelerinde çeviri dersleri, sorunları, çözümleri. Türkçe ve çeviri sorunları çalıştayı. 7-9 Mart 2008. Ankara: Türk Dil Kurumu Yayınları.

Üçok, N. (2004). Genel dilbilim (Lenguistik). İstanbul: Multilingual.

Vardar, B. (2001). Dilbilim temel kavram ve ilkeleri. İstanbul: Multilingual. 